\title{
Effect of long-term oral administration of $\beta$-glucan as an immunostimulant or an adjuvant on some non-specific parameters of the immune response of turbot Scophthalmus maximus
}

\author{
M. Ogier de Baulny ${ }^{1}$, C. Quentel ${ }^{1, *}$, V. Fournier ${ }^{1}$, F. Lamour ${ }^{1}$, R. Le Gouvello ${ }^{2, * *}$ \\ 'CNEVA BREST/Laboratoire de Pathologie des Animaux Aquatiques, BP 70, F-29280 Plouzané, France \\ ${ }^{2}$ SANOFI, Santé et Nutrition Animale, BP 126, Z.I. de la Ballastière, F-33501 Libourne cedex, France
}

\begin{abstract}
A commercial $\beta$-glucan known for its immunostimulatory effects in several fish species was tested in turbot Scophthalmus maximus L., both as an oral immunostimulant and as an adjuvant for oral vaccination. Some non-specific immune parameters were tested after a $5 \mathrm{wk}$ feeding period with a commercial diet mixed with yeast $\beta$-glucan. Furthermore, during the last $5 \mathrm{~d}$ of the feeding period, half of the fish were orally vaccinated by mixing the commercial pellets with an anti-vibriosis vaccine (Vibriffa bain ND). The oral administration of $\beta$-glucan induced no reduction in mortality after a challenge with a virulent Vibrio anguillarum (strain 408). In contrast, a single oral vaccination resulted in protection against $V$. anguillarum. The use of $\beta$-glucan as an adjuvant did not reduce the mortality rate more than did the single vaccination. An increase in white blood cell count was observed after the administration of only $\beta$-glucan. The plasma complement activity was not influenced by any of the treatments. In contrast, lysozyme activity was enhanced after administration of the adjuvanted vaccine. An increase in the chemiluminescent response of opsonised zymosan-stimulated head-kidney leucocytes was less obvious and no significant results were recorded.
\end{abstract}

KEY WORDS: Turbot - $\beta$-Glucan - Oral vaccination · Immune response

\section{INTRODUCTION}

Antibiotics and other chemotherapeutics are today widely used by fish farmers to control disease outbreaks. But the secondary effects of these treatments upon the environment may be of importance. Indeed, they may result in a selection of resistant microbial strains and even render fish susceptible to secondary viral infections (Siwicki et al. 1989). Thus, disease control in aquaculture should focus on preventative measures. As commercial vaccines remain costly for fish producers and are not efficacious at present against many commercially important bacterial diseases and

\footnotetext{
-Addressee for correspondence. E-mail: vabr10@calvacom.fr - Present address: STERMOR, Kerfahler, F-56760 Pénestin, France
}

those caused by viruses (Rad et al, 1992), an interest in immunostimulants to improve fish health has developed in recent years. Among substances involved in fish protection, research has already focused on polysaccharides such as lentinan, schizophyllan, scleroglucan and zymosan (Yano et al. 1991)

Yeast-extracted $\beta$-1,3-glucans are of particular interest in fish disease prevention (Anderson 1992). They have been shown to enhance the disease resistance of several fish species, such as carp Cyprinus carpio L. (Yano et al. 1991), Atlantic salmon Salmo salar (Robertsen et al. 1990), yellowtail Seriola quinqueradiata (Matsuyama et al. 1992), rainbow trout Oncorhynchus mykiss (Jeney \& Anderson 1993), brook trout Salvelinus fontinalis (Anderson \& Siwicki 1994) and African catfish Clarius gariepinus (Yoshida et al. 1995), against various major bacterial pathogens including Vibrio 
anguillarum, Vibrio salmonicida and Yersinia ruckeri (Robertsen et al. 1990) and Aeromonas hydrophila (Yoshida et al. 1995).

Glucans are known to stimulate the non-specific mechanisms of the immune response in mammals (DiLuzio 1985). In fish, Yano et al. (1991), following in vitro studies, suggested that the effect of $\beta$-1,3-glucans may be associated with the activation of the alternate complement pathway. After intra-peritoneal (IP) injection of Atlantic salmon with a $\beta-1,3$-glucan, Engstad et al. (1992) showed an increase in plasma spontaneous haemolytic activity and lysozyme activity. Matsuyama et al. (1992) also obtained enhanced serum alternate complement pathway and lysozyme activities after an IP injection of yellowtail with schizophyllan or scleroglucan. In addition, they observed an increase in the phagocytic activity of pronephros cells.

$\beta-1,3$-glucans are usually given by IP injection and the protection induced appears to be dosage-dependent (Chen \& Ainsworth 1992). However, oral administration is of obvious interest, due to its convenience to fish farmers and lack of stress for fish. Few data exist concerning oral administration protocols or dosages in farmed fish species. Today, no standardized protocol exists and recommendations may vary according to the molecule tested.

$\beta$-Glucans can also be used as vaccine adjuvants particularly with bacterin vaccines. Indeed, Aakre et al. (1994) showed that the presence of a glucan adjuvant in an anti-Aeromonas vaccine gave a high relative percent survival in Atlantic salmon after a virulent challenge. Furthermore, these authors showed that the use of $\beta$-glucan as an adjuvant led to higher serum antibody levels compared to vaccine given alone. Similarly, Jeney \& Anderson (1993) obtained enhanced immune responses in rainbow trout given a glucanadjuvanted anti-Yersinia ruckeri vaccine. Most of the studies have been performed in salmonids (Anderson 1992) and protocols for use of glucans as adjuvants also remain highly variable

This study was undertaken to investigate the effect of a $\beta-1,3 / \beta-1,6$ linked glucan (Macrogard ${ }^{\circledR}$ ), which is known to be effective in salmonids (Robertsen et al. 1990, Onarheim 1992a, b, Raa et al. 1992). In our study, Macrogard was orally administered to turbot Scophthalmus maximus L, and the effect of long-term oral administration on some parameters of the immune response explored. The immunostimulant was either given alone or administered with an immunisation against the Vibrio anguillarum bacterin to investigate its 'adjuvant effect' This combined administration was compared both with untreated controls and with the effect of a single oral anti-vibriosis vaccination. Some non-specific immune parameters potentially involved in protection were studied post-treat- ment, namely circulating leucocyte number, plasma lysozyme and complement activities and head-kidney leucocyte phagocytic activity, as well as the acquired protection of fish given the different treatments against $V$. anguillarum.

\section{MATERIAL AND METHODS}

Fish. 1200 turbot, weighing about $30 \mathrm{~g}$ at the beginning of the experiment and $50 \mathrm{~g}$ at sampling time, were group-housed in 8 experimental $200 \mathrm{l}$ tanks (EWOS, $1 \times 1 \mathrm{~m}$ ). These tanks were supplied with filtered, welloxygenated and thermoregulated seawater (salinity $35 \%$; temperature $20 \pm 1^{\circ} \mathrm{C}$ ). Fish were acclimatized 3 wk prior to initiating experiments and water renewal $\left(150 \mathrm{l} \mathrm{h}^{-1}\right)$ was maintained throughout the stocking and experimental period.

Reagents. The $\beta$-glucan Macrogard ${ }^{\text {was }}$ warchased from Mackzymal (Tromsø, Norway). It is an insoluble yeast glucan from Saccharomyces cerevisiae cell walls. The antigen for oral vaccination was a commercial formalin-killed anti-vibriosis vaccine (Vibriffa bain ${ }^{(1)}$; Rhône-Mérieux, Lyon, France) containing about $2 \times$ $10^{11}$ killed bacteria $\mathrm{ml}^{-1}$.

Feeding preparation. Three different experimental diets were prepared.

The experimental diet for oral immunostimulation was prepared by mixing together commercial pellets (Ecoline ${ }^{\otimes}$; Aqualim, Nersac, France) and $\beta$-glucan powder; a vegetable oil was then added to the mixture at a rate of $2 \%$ in order to coat the pellets. The amount of glucan added to the food was $2 \mathrm{~g} \mathrm{~kg}^{-1}$. The coated food was prepared and the daily ration per tank was sealed in plastic bags and stored at $-20^{\circ} \mathrm{C}$ until used.

The vaccine food was prepared daily during the vaccination period. The Vibriffa bain vaccine had been previously diluted in saline $(9 \% \mathrm{NaCl}$. The vaccine suspension was added to the food at a proportion of $1 / 5$. The quantity of vaccine added to the food was calculated so that the theoretical amount of bacteria ingested daily by each fish was $4 \times 10^{9}$ (Vigneulle 1991).

The 'immunostimulant and vaccine' coated food was obtained by adding the vaccine-diluted suspension to the immunostimulant-coated food, both prepared as previously described.

Feeding regimes. The oral immunostimulation lasted $5 \mathrm{wk}$. The oral vaccination was performed for 5 d following the protocol defined by Vigneulle (1991)

Four different groups were established corresponding to 4 different treatments. Each group comprised 2 tanks of 150 fish. Fish were fed twice a day at $1.9 \%$ $\mathrm{d}^{-1}$ of body weight throughout the experiment. The 
control (C) group received normal commercial pellets. The immunostimulated (IS) group was given the $\beta$ glucan-coated food for $35 \mathrm{~d}$. At the same time, the 'immunostimulated and vaccinated' (IS+VAC) group received $\beta$-glucan-coated pellets for $30 \mathrm{~d}$ and then, for $5 \mathrm{~d}$, a $\beta$-glucan- and vaccine-coated food. The vaccinated (VAC) group was fed with normal pellets for $30 \mathrm{~d}$ and received the vaccine food for the last $5 \mathrm{~d}$ of the treatment period.

After $35 \mathrm{~d}$ of experimental feeding, blood samples were taken from 10 fish of each group to determine plasma parameters, on Days 1, 8, 14 and 21 after the end of the treatment period. Head kidneys were also removed from 10 fish of each group on Days 1 and 14 to perform phagocytic activity assays. Twenty-eight days after the end of the feeding period, the remaining fish in each tank were experimentally injected with Vibrio anguillarum serotype 1 (strain 408; Baudin Laurencin 1981) to compare their resistance to the pathogen.

Blood sampling. Blood samples were collected in heparinised vacuum tubes (Vacutainer ${ }^{(\mathbb{Q}}$, Becton Dickinson Vacutainer Systems, Meylan, France) from the caudal vessel. Approximately $1 \mathrm{ml}$ of whole blood was taken from each fish. Fifty $\mu \mathrm{l}$ of each whole blood sample was immediately removed and stained for white blood cell counts (WBCC). The blood was then centrifuged at $900 \times \mathrm{g}$ for $10 \mathrm{~min}$ at $4^{\circ} \mathrm{C}$, and the resulting plasma samples collected, aliquoted and stored at $-70^{\circ} \mathrm{C}$ until analysis.

Experimental infection. Virulent Vibrio anguillarum suspension was prepared using an $18 \mathrm{~h}$ bacterial culture on trypticase soy agar supplemented with $1.5 \%$ $\mathrm{NaCl}$ (TSA 1.5). Fish were infected by IP injection of about $2 \times 10^{6}$ bacteria per fish. Deaths were recorded over $15 \mathrm{~d}$. Dead fish were collected daily and necropsied. Kidney samples were streaked on TSA 1.5 and the presence of $V$. anguillarum was verified through seroagglutination using a polyclonal anti- $V$. anguillarum 408 serum.

For each treatment, the relative per cent survival (RPS) was calculated as follows (Ellis 1988):

$$
\text { RPS }=\frac{\left(\begin{array}{c}
\text { Mortality }(\%) \text { of untreated controls }- \\
\text { Mortality }(\%) \text { of treated group }
\end{array}\right)}{\text { Mortality }(\%) \text { of untreated controls }} \times 100
$$

Total white blood cell count. The WBCC was conducted employing a Thoma's haemocytometer and Kekic \& Ivanc's method (1982), using Giemsa solution as the diluent (1/400) and stain.

Lysozyme activity. The turbidimetric assay for lysozyme was carried out according to Parry et al. (1965) as modified by Grinde et al. (1988). Briefly, test plasma $(100 \mu \mathrm{l})$ was added to $2 \mathrm{ml}$ of a suspension of Micrococcus lysodeikticus $\left(0.2 \mathrm{mg} \mathrm{ml}^{-1}\right)$ in a $0.05 \mathrm{M}$ sodium phosphate buffer, $\mathrm{pH} 6.2$. The reactions were carried out at $20^{\circ} \mathrm{C}$ and absorbance at $520 \mathrm{~nm}$ was measured between 1 and 4 min on a spectrophotometer (DU40; Beckmann, Gagny, France). A lysozyme activity unit was defined as the amount of enzyme producing a decrease in absorbance of $0.001 \mathrm{~min}^{-1}$ at $20^{\circ} \mathrm{C}$.

Haemolytic complement activity. The assay of the classical complement pathway activity was carried out using the procedure of Yano (1992) with some modifications: total reaction volume and sheep red blood cells (SRBC) count were reduced, respectively, from 1.5 to $0.15 \mathrm{ml}$ and from $5 \times 10^{8}$ to $1 \times 10^{7} \mathrm{SRBC}$, to permit the use of microplates.

SRBC were washed 3 times with an EDTA gelatin veronal buffer (Yano 1992) and resuspended to yield a $2 \%$ concentration $\left(2 \times 10^{8}\right.$ cells $\left.\mathrm{ml}^{-1}\right)$ in a glucose gelatin veronal buffer (Yano 1992). SRBC were sensitised with heat-inactivated turbot anti-SRBC serum diluted to $1 / 75$, a dilution permitting complete haemolysis. $\mathrm{SRBC}$ were incubated at $30^{\circ} \mathrm{C}$ for $30 \mathrm{~min}$, with shaking every 5 min.

Test plasma samples were first diluted to $1 / 128$ in order to suppress natural haemolysin activity (author's pers. obs.), then volumes of the diluted plasma 10.01 , $0.02, \ldots, 0.09 \mathrm{ml})$ were combined with gelatin veronal buffer $(0.09,0.08, \ldots, 0.01 \mathrm{ml})$ in the microplate and $0.05 \mathrm{ml}$ of the sensitised SRBC suspension was added per well. Complete haemolysis was obtained by mixing $0.05 \mathrm{ml}$ of sensitised SRBC with $0.1 \mathrm{ml}$ of distilled water (positive control). The negative control consisted of $0.05 \mathrm{ml}$ sensitised SRBC mixed with $0.1 \mathrm{ml}$ of gelatin veronal buffer.

After incubation at $20^{\circ} \mathrm{C}$ for $60 \mathrm{~min}$, microplates were centrifuged at $800 \times g$ for $5 \mathrm{~min}$. The optical density of the supernatant was measured in a microplate reader (IEMS; Labsystems, Cergy-Pontoise, France) at $490 \mathrm{~nm}$. A lysis curve was obtained by plotting the percentage of haemolysis against the volume of plasma added $(\mathrm{ml})$. The volume which yielded $50 \%$ haemolysis was determined and used for calculating the complement activity of the sample (CH50 units $\mathrm{ml}^{-1}$ ) as described by Sakai (1981)

CH50 units $\mathrm{ml}^{-1}=\frac{\text { Dilution coefficient of plasma }}{\mathrm{ml} \text { for } 50 \% \text { haemolysis }} \times \frac{0.15 \mathrm{ml}}{7.5 \mathrm{ml}}$

Phagocytic activity of head-kidney leucocytes. This was estimated using an indirect method, i.e. the chemiluminescence response of zymosan-activated leucocytes. Head kidney cell suspensions were prepared as previously described by Angelidis et al. (1988). Head kidney was removed and passed through a metal filter (Cellector Belco filters, $100 \mu \mathrm{m}$ ). Cells were harvested, suspended in heparinized (10 USP $\mathrm{ml}^{-1}$ ) Hank's balanced salt solution (HBSS) without 
phenol red, and kept on crushed ice. The leucocyte concentration was adjusted to $5 \times 10^{6}$ viable cells $\mathrm{ml}^{-1}$ after cell viability was evaluated by a trypan blue exclusion test. Luminol was prepared according to the method described by Scott \& Klesius (1981), to give a stock solution of $8 \mathrm{mM}$, and stored for a week at $4^{\circ} \mathrm{C}$ in tubes wrapped in aluminium foil. The stock solution was diluted 4 to $6 \mathrm{~h}$ before use in distilled water to obtain a working solution of $0.05 \mathrm{mM}$. The procedure to opsonise zymosan was a modification of that used by Scott \& Klesius (1981). Zymosan and pooled serum from healthy turbot (non-experimental fish) were incubated together at $30^{\circ} \mathrm{C}$ for $45 \mathrm{~min}$. The zymosan final concentration was $5 \mathrm{mg} \mathrm{ml}^{-1}$. Duplicate assay vials received $0.1 \mathrm{ml}$ cell suspension, $0.1 \mathrm{ml}$ opsonised zymosan, and $0.05 \mathrm{ml}$ luminol. Control vials were prepared by replacing zymosan with HBSS. Chemiluminescence (CL) values were recorded at 10 min intervals for $1 \mathrm{~h}$ on a $1250 \mathrm{LKB}$ luminometer (Pharmacia, Saint-Quentin en Yvelines, France), to determine CL peak intensities.

Statistical methods. Statistical analysis was performed using a computerised STATITCF statistical system (ITCF, Paris, France). Results from the 2 tanks of each group were analysed for heterogeneity and then grouped together when no statistical difference existed. Results on the immune parameters for the different treatments were compared to each other using a Student's t-test, based on an average of 20 fish per regime, or 10 fish per regime for the CL response. Mortality rates were analysed by a $\chi^{2}$ test. Each regime was compared to the control group and, to evaluate the 'adjuvant effect', the IS+VAC group was also compared to the VAC group in order to establish if the variations observed were due to the single vaccination or to the combined effect of glucan and vaccine

\section{RESULTS}

\section{Total white blood cell count}

Results are given as the mean of 20 fish per day and per regime and are shown in Fig. 1. Some variation in WBC number was observed due to the effect of the different treatments.

The total WBCC was always higher in the IS group compared to the control group, but this elevation was only significant on Days 8 and 21 . The oral vaccination (VAC group) induced no variation in WBCC. No significant difference was observed between the IS+VAC group and the control group on any sampling day. On Day 21, the WBCC in the IS+VAC group was significantly higher than in the VAC group.
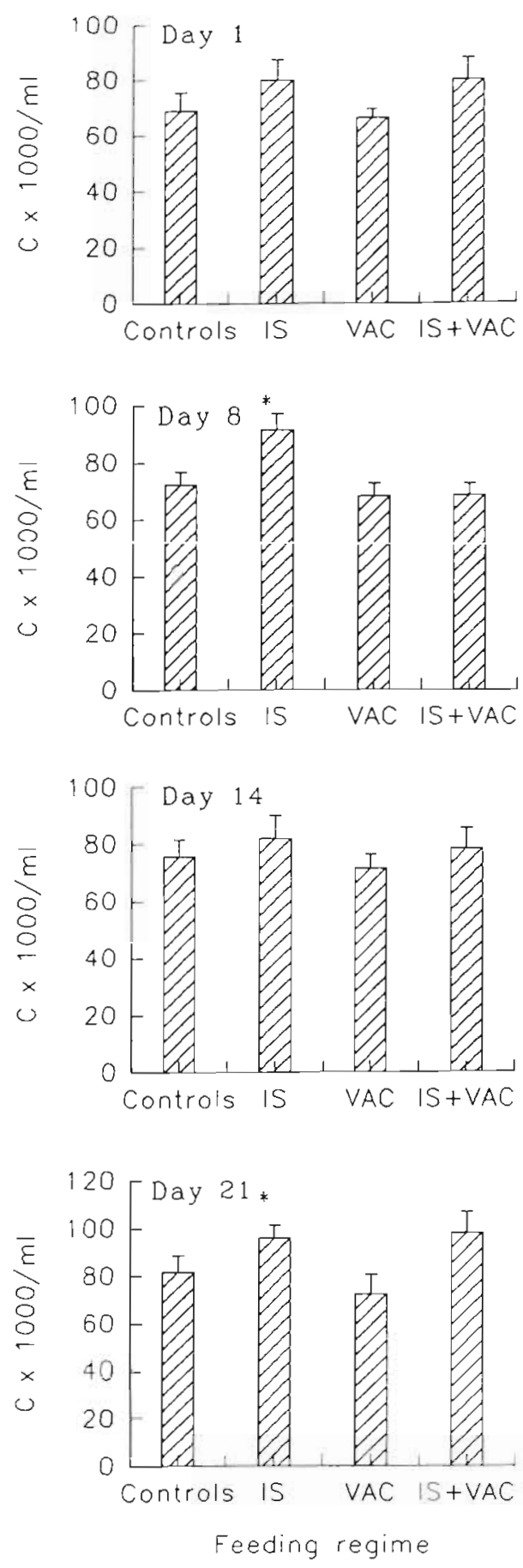

Fig. 1. Scophthalmus maximus. Effect of the different treatments on total white blood cell counts on each sampling day. Results are means $+S E_{1} n=20$ fish per group. "Significant difference ( $p<0.05$ using a Student's $t$-test to compare control group and treated group)

\section{Plasma lysozyme activity}

Fig. 2 shows that the lysozyme activity levels were higher the first $2 \mathrm{~d}$ of sampling than on Day 14 or 21 . 

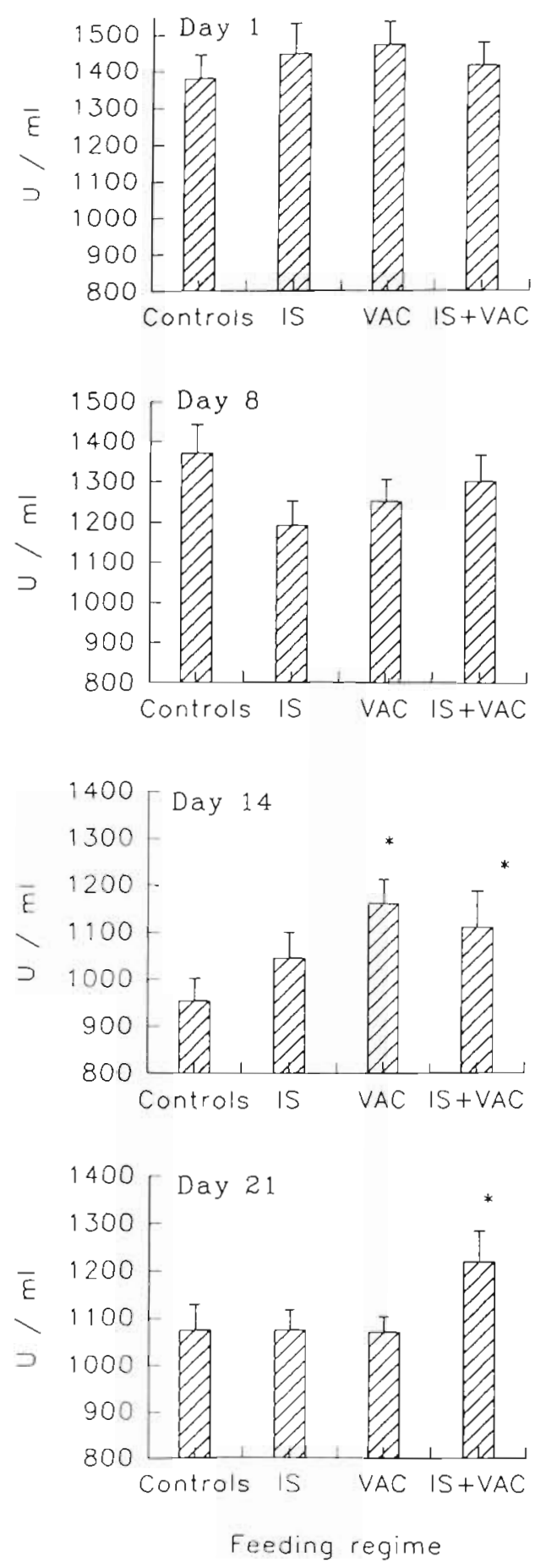

Fig. 2. Scophthalmus maximus. Effect of the different treatments on the plasma lysozyme activity on each sampling day. Results are means $+\mathrm{SE}, \mathrm{n}=20$ fish per group. 'Significant difference $(p<0.05$ using a Student's t-test to compare control group and treated group)

Generally, plasma lysozyme activity was not affected by administration of the immunostimulant (IS group), whatever the sampling day. The vaccination (VAC group) led to a significant increase in lysozyme activity only on Day 14. No significant difference was observed between fish from the control group and the IS+VAC treated fish on Day 1 or 8 . In contrast, the IS+VAC group developed significantly higher lysozyme activities on both Days 14 and 21 when compared to the control group. When compared to the VAC group, lysozyme activity was enhanced in this group on Day 21 only.

\section{Plasma complement activity}

As observed in Fig. 3, none of the treatments, IS, VAC or IS+VAC, induced any change in the studied parameter, whatever the sampling day.

\section{Phagocytic activity of the head-kidney leucocytes}

The chemiluminescent response of head-kidney phagocytes stimulated by opsonised zymosan increased progressively, reached a peak between 20 and $30 \mathrm{~min}$, and then decreased slightly (data not shown). Only the maximum value obtained was retained for analysis (Fig. 4). Just after the end of the feeding period, i.e. at Day 1, the CL response was higher $(\mathrm{p}<0.1)$ in fish given the glucan (IS group). The single vaccination (VAC group) induced no variation of this parameter. In contrast, the CL peak was enhanced in the IS+VAC group when compared to the control group ( $p<0.1)$. However, when compared to the VAC group this elevation was not significant. At Day 14 , zymosan-stimulated CL response was highly variable between fish in all the experimental groups and, in spite of an enhanced response in all treated groups, results obtained for the IS group and the VAC group were not significantly different from those of the $C$ group. Due to less variability in the IS+VAC group, the mean CL response in this group was significantly higher than in the $\mathrm{C}$ group.

\section{Experimental infection}

Mortality began $24 \mathrm{~h}$ after the virulent Vibrio anguillarum inoculation and lasted $5 \mathrm{~d}$ (Fig. 5). Classical signs of haemorrhagic septicemia were observed, i.e. internal haemorrhages on the visceral organs and in the musculature and ascites, and all dead fish were positive for $V$. anguillarum. The post-challenge mortality rate was the same in untreated controls and in fish given the immunostimulant, i.e. 41 and $44 \%$, respectively.

In contrast, after the IS+VAC treatment and the VAC treatment, the mortality rate dropped to $16 \%$ for 

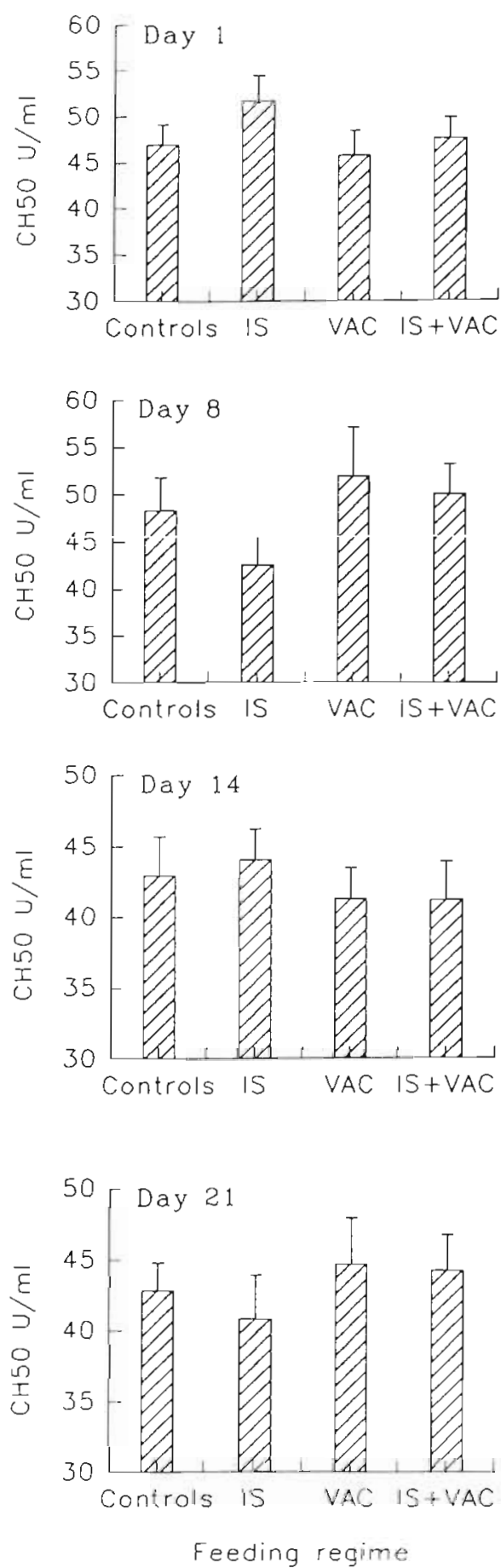

Fig. 3. Scophthalmus maximus. Effect of the different treatments on the plasma complement activity on each sampling day. Results are means $+S E, n=20$ fish per group. 'Significant difference ( $p<0.05$ using a Student's t-test to compare control group and treated group)

the former and $19.5 \%$ for the latter group, corresponding to protection rates of 60.9 and $52.4 \%$ respectively.
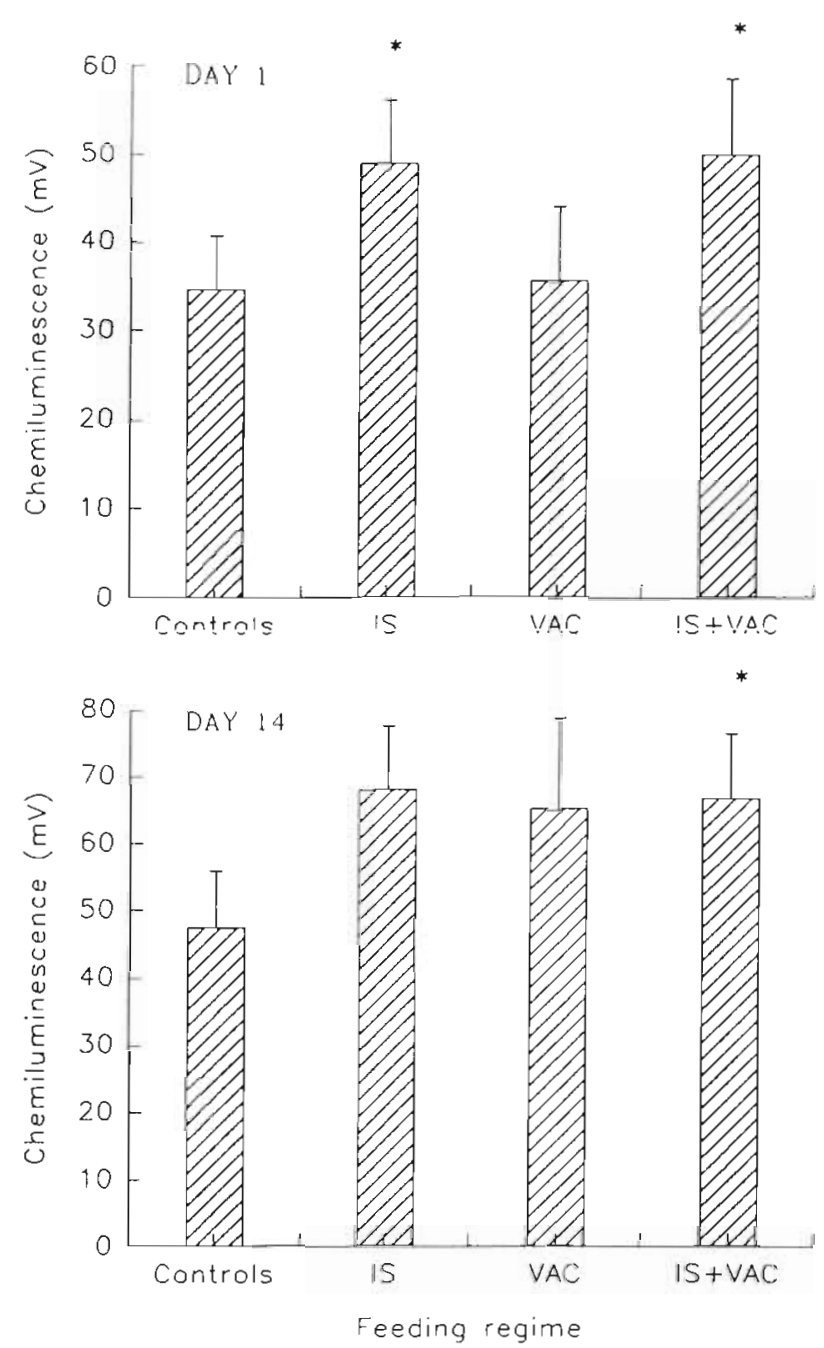

Fig. 4. Scophthalmus maximus. Effect of the different treatments on the chemiluminescence response of head-kidney leuko cytes on Days 1 and 14. Results are means $+\mathrm{SE}, \mathrm{n}=10$ fish per group. 'Significant difference $(p<0.05$ using a Student's $t$-test to compare control group and treated group)

\section{DISCUSSION}

Previous studies have shown great variability in the effect of $\beta$-glucans on total WBCC. Siwicki et al. (1994) reported contradictory effects of $\beta$-glucans on rainbow trout leucocyte numbers after an oral exposure. In the first experiment they obtained an elevated leucocyte number in immunostimulated fish, but in the second they observed no effect. In contrast, Jeney \& Anderson (1993) observed a rise in the WBCC after injection or bath administration of a barley-extracted glucan in rainbow trout. They showed an initial decrease in WBCC $6 \mathrm{~h}$ after immunostimulation, followed by an increase at $12 \mathrm{~h}$ and a greater increase at Day 2 after injection, and at Day 3 after bath treatment. Further- 


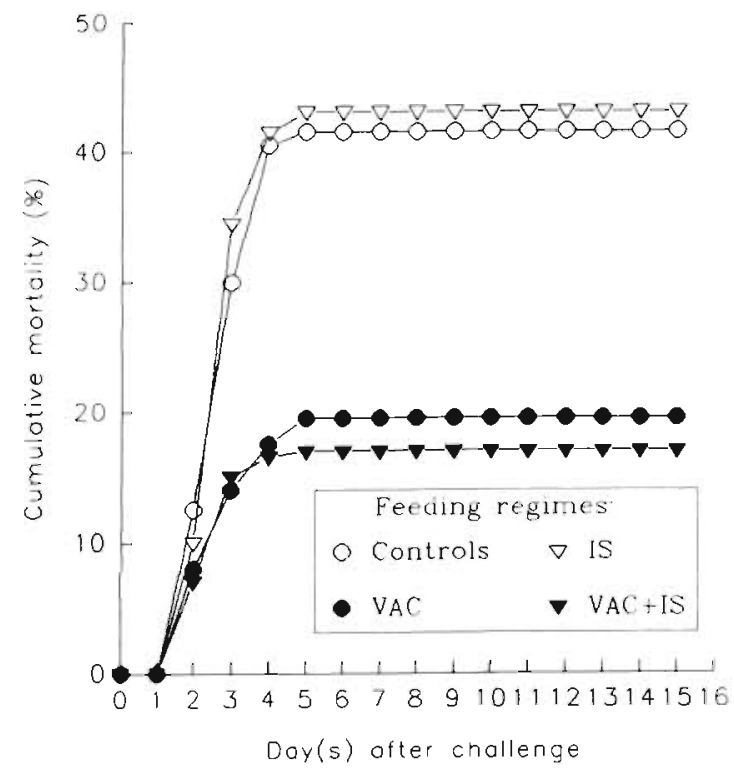

Fig. 5. Scophthalmus maximus. Cumulative mortality rate (\%) after infectious challenge with Vibrio anguillarum (strain 408)

more, WBCC was always higher in immunostimulated fish 10 d later. In the present study, although significant only at Days 8 and 21, WBCC was higher from Day 1 to Day 21 after oral administration of the $\beta$-glucan. This rise in WBCC may imply a mobilization of the WBC population in response to $\beta$-glucans. In fact, as the glucan is orally administered, no development of an inflammatory reaction could be suspected which would have increased the number of circulating leucocytes. Furthermore, this WBC mobilization lasted at least until Day 21 after the end of glucan administration.

The effect of a single or adjuvanted vaccine upon WBCC was reported by Jeney \& Anderson (1993), who obtained only a slight increase in leucocyte number after bath administration of a Yersinia ruckeri antigen in rainbow trout, whereas the administration of a glucan-adjuvanted vaccine induced a more marked increase in WBCC. In contrast, the present results showed no effect on WBCC after either the single vaccination or the administration of adjuvanted vaccine. A possible interaction between the vaccine and the adjuvant could have masked the effect of the $\beta$-glucan on WBCC.

It must be pointed out that, in the present work, the mean lysozyme activity values obtained from control groups varied according to the different sampling days. This remains unexplained, as all the measurements were performed on the same date upon defrosted plasma samples and according to a classical method used to determine lysozyme activity in salmonids (Jørgensen et al, 1993). No effect of
Macrogard on plasma lysozyme activity was observed in the present work, in spite of the fact that this molecule is produced by macrophages and granulocytes (Alexander \& Ingram 1992). This suggests that if the number of leucocytes was enhanced after long-term oral administration of this $\beta$-glucan, no rise in their activity was induced. Engstad et al. (1992) observed an increased lysozyme activity from Day 7 to Day 28 after a single IP injection of Macrogard in salmonids, and Jørgensen et al. (1993) obtained the same result in rainbow trout 7,14 and $21 \mathrm{~d}$ after a M-glucan injection. This could indicate that Macrogard has a greater effect on plasma non-specific defences after injection rather than after oral administration. The difference between the 2 routes of administration may be due to the inflammatory reaction induced by the IP injection which could enhance the setting of the immune response. The degradation and absorption of the glucan in the digestive tract after oral administration must also be taken into account, as this may modify the effect of the molecule on the immune system.

In the present work, an elevation in lysozyme activity occurred in the VAC group only on Day 14, but in the IS+VAC group the increase was significant on Days 14 and 21. Increased lysozyme levels may occur after an antigenic stimulation (Alexander \& Ingram 1992) and the present results showed that the use of glucan could potentiate the effect of the vaccine.

Complement, another component of the non-specfic immune response also produced by leucocytes, was studied in the present work. The $\beta$-glucan when given alone had no effect on the classical complement pathway activity. The study of Yano et al. (1991) showed that in vitro pre-incubation of a carp serum with glucans inhibited the alternate complement pathway; as a consequence, they suggested that the protective effect of $\beta$-glucans may be associated with the activation of the alternate complement pathway. It can be assumed that the effect of $\beta$-glucan takes place at the $C 3$ activation step of the complement serial 'cascade' reaction and thus does not affect the classical pathway. In mammals, polysaccharides such as zymosan are known to induce the $\mathrm{C} 3$ activation step of the complement reaction (Bach \& Lesavre 1989) and this might also be the case in fish.

In contrast to the plasma parameters, the oral administration of glucan did induce an enhanced phagocytic activity of head-kidney leucocytes on both Days 1 and 14. This is in agreement with the augmentation of phagocytosis by circulating leucocytes observed after bath or injection administration of glucan by Jeney \& Anderson (1993) in rainbow trout. Siwicki et al. (1994) also obtained a higher phagocytic activity after feeding immunostimulants to rainbow trout for $1 \mathrm{wk}$. These 
results concur with the general hypothesis of a strong action of $\beta$-glucan on the non-specific immune mechanisms (Raa et al. 1992). Furthermore, although the CL response after a single oral vaccination was never significantly higher than in controls in the present study, the administration of the adjuvanted vaccine was followed by an increased CL response on both Days 1 and 14 . This could indicate that $\beta$-glucan acts strongly on this parameter compared to the vaccination effect. In fact, the $\beta$-glucan seems to influence phagocytic activity by itself rather than optimize the vaccine. However, $1 \mathrm{~d}$ after oral administration was probably too soon to observe any effect of the vaccine in the head kidney, as the 'antigen processing' might not have occurred by that time. In addition, it must be noted that the mean CL values obtained at Day 14 in each of the treated groups were similar but not significantly different from the controls, except for the IS+VAC group, due to their high variability. It is therefore difficult to know whether the significant elevation in phagocytic activity in the IS+VAC group is due to the glucan or to the vaccine or to both.

In contrast to the non-specific immune parameters, no effect upon mortality in turbot was observed when the $\beta$-glucan was given alone in the present study. Previous studies have shown that extensive mortality reductions were obtained following the use of glucans in salmonids. Onarheim (1992b) observed a $41 \%$ reduction in the mortality of Atlantic salmon challenged with furunculosis $42 \mathrm{~d}$ after a $14 \mathrm{~d}$ glucan feeding period, and Raa et al. (1992) obtained a marked reduction in mortality after carrying out a furunculosis challenge soon after $5 \mathrm{wk}$ of Macrogard feeding. Furthermore, Siwicki et al. (1994) observed a $40 \%$ reduction in mortality after a 1 wk $\beta$-glucan exposure. This difference between previous and present results might be related to the species but also to the $28 \mathrm{~d}$ interval between the end of the immunostimulation and the virulent challenge. In fact, in order to test for a possible 'adjuvant effect' in addition to the 'immunostimulant effect' of $\beta$-glucan, the challenge was performed $4 \mathrm{wk}$ after vaccination in order to allow the specific immune mechanisms to develop after vaccination. The challenge method also needs to be taken into account. In this study, the IP route was chosen to perform the virulent challenge in order to be sure of the number of bacteria challenging each fish. This allows a sufficient mortality rate to be obtained in controls, as is recommended when testing vaccines in fish (Amend 1981). The mortality rate attained in controls in this study may have masked the effect of the $\beta$-glucan. In fact, a less drastic challenge such as in the bath or cohabitation approach could have revealed the role of local intestinal mechanisms after oral administration of glucan and/or vac- cine. In addition, IP challenge involves the systemic immune response and may mask local protection (Vigneulle 1991)

Furthermore, the use of 3 -glucan as an adjuvant showed no effect on the mortality rate compared to that obtained after a single vaccination. The study of Aakre et al. (1994) in Atlantic salmon vaccinated against furunculosis produced contradictory results; they obtained a higher survival rate with glucancontaining vaccine compared to a single bacterin vaccine, when fish were challenged 7 wk after vaccination. On the other hand, a challenge performed $12 \mathrm{wk}$ after a booster vaccination showed no difference in protection between the glucan-adjuvanted and nonadjuvanted vaccine.

The line of vaccination with regard to the immunostimulation period may play a role in the development of an 'adjuvant effect'. In the present work, the vaccination occurred during the last $5 \mathrm{~d}$ of the glucan administration period, and this might explain the results obtained. Anderson et al. (1989) reported an enhanced non-specific (phagocytic indices, neutrophil enzyme activities, number and percentage of adherent cells) and specific (antibody secreting cells enumerated by plaque-forming cells assays) immune response in rainbow trout when administering an immunostimulant, levamisole, during or after immunisation with the Yersinia ruckeri O-antigen. No variation of non-specific immune parameters occurred when the adjuvant was given before immunisation. In spite of the differences between glucan and levamisole, the relative times of vaccination and immunostimulation may be of importance.

The strong mortality reduction obtained after a single oral vaccination must be highlighted. This confirms the relative efficacy of oral immunisation in turbot when compared to other fish species. Indeed, Baudin Laurencin \& Batellier (1986) managed to protect turbot against vibriosis through this vaccination method. Dec et al. (1990) also obtained a $70 \%$ protection after oral anti-vibriosis vaccination in turbot and sea bass, whereas protection rates remain very low in salmonids after oral vaccination against both Vibrio anguillarum and Yersinia ruckeri (Ellis 1985, Baudin Laurencin \& Batellier 1986, Vigneulle 1991).

Results obtained from this work did not enable us to draw a definite conclusion about the effect of Macrogard. orally administered to turbot. In spite of an enhanced non-specific response following the oral administration of $\beta$-glucan to turbot, further studies need to be carried out to improve the efficacy of $\beta$-glucan products and to assess administration schedules, duration of protection and the possible oral adjuvant potential for this species, which responds well to oral immunisation. 


\section{LITERATURE CITED}

Aakre R, Wergeland HI, Aasjord PM, Endresen C (1994) Enhanced antibody response in Atlantic salmon (Salmo salar L.) to Aeromonas salmonicida cell wall antigens using a bacterin containing $\beta$-1,3-M-Glucan as adjuvant Fish Shellfish Immunol 4:47-61

Alexander JB, Ingram GA (1992) Noncellular nonspecific defence mechanisms of fish. Ann Rev Fish Dis 2:249-279

Amend DF (1981) Potency testing of fish vaccines. International Symposium on Fish Biologics: Serodiagnostics and Vaccines, Leetown, W. Va., USA, 1981. Dev Biol Stand 49. $447-454$

Anderson DP (1992) Immunostimulants, adjuvants and vaccine carriers in fish: applications to aquaculture. Ann Rev Fish Dis 2:281-307

Anderson DP, Siwicki AK (1994) Duration of protection against Aeromonas salmonicida in brook trout immunostimulated with glucan or chitosan by injection or immersion. Prog Fish Cult 56:258-261

Anderson DP, Siwicki AK, Dixon OW, Lizzio EF (1989) Immunostimulation by levamisole in rainbow trout (Salmo gairdneri) in vivo. In: Ahne W, Kurstak $E$ (eds) Viruses of lower vertebrates. Springer-Verlag, Berln, p $469-478$

Angelidis P, Baudin Laurencin F, Youinou P (1988) Effects of temperature on chemiluminescence of phagocytes from sea bass, Dicentrarchus labrax L. J Fish Dis 11:281-288

Bach JF, Lesavre P (1989) Immunologie. Flammarion \& Cle, Paris

Baudin Laurencin F (1981) Vibrio strains antisera in France. International Symposium on Fish Biologics: Serodiagnostics and Vaccines, Leetown, W. Va., USA, 1981 Dev Biol Stand 49:257-259

Baudin Laurencin F, Batellier FY (1986) Protection immunitaire du turbot (Scophthalmus maaximus) contre la vibriose. In: Jaspers E, Vivares CP, Bonami JR (eds) Pathology in marine aquaculture. Special publication no. 9. European Aquaculture Society, Bredene, p 391-403

Chen D. Ainsworth AJ (1992) Glucan administration potentiates immune defence mechanisms of channel catfish. $J$ Fish Dis 15:295-304

Dec C, Angelidis P, Baudin Laurencin F (1990) Effect of oral vaccination against vibriosis in turbot (Scophthalmus maximus) and sea-bass (Dicentrarchus labrax). J Fish Dis 13: $369-376$

DiLuzio NR (1985) Update on the immunomodulating activities of glucans. Spring Semin lmmunopathol 8:387-400

Ellis AE (1985) Development of fish vaccines: strategies and future considerations. In: Ellis AE (ed) Fish and shellfish pathology. Academic Press, London, p 41-52

Ellis AE (ed) (1988) Fish vaccination. Academic Press, London

Engstad RE, Robertsen B, Frivold E (1992) Yeast-glucan induces increase in lysozyme and complement-mediated haemolytic activity in Atlantic salmon blood. Fish Shellfish Immunol 2:287-297

Grinde B, Jollès J, Jollès P (1988) Purification and characterization of two lysozymes from rainbow trout (Salmo gairdneri). Eur J Biochem 173:269-273

Responsible Subject Editor: D. W. Bruno, Aberdeen, Scotland, UK
Jeney G, Anderson DP (1993) Glucan injection or bath exposure given alone or in combination with a bacterin enhance the non-specific defence mechanisms in rainbow trout (Oncorhynchus mykiss). Aquaculture 116:315-329

Jorgensen JB, Sharp GJE, Secombes CJ, Robertsen B (1993) Effect of a yeast-cell-wall glucan on the bactericidal activ. ity of rainbow trout macrophages. Fish Shellfish Immunol $3: 267-277$

Kekıc H, Ivanc A (1982) A new direct method for counting fish blood cells. Ichthyologia 14(1):55-58

Matsuyama $H$, Mangindaan REP, Yano T (1992) Protective effect of schizophyllan and scleroglucan against Streptococcus sp. infection in yellowtail (Seriola quinqueradiata). Aquaculture 101:19?-203

Onarheim AM (1992a) The glucan way to fish health. Fish Farming International August 1992, p 32-33

Onarheim AM (1992b) Now a yeast extract to fortify fish. Fish Farmer July/August 1992, p 45

Parry RM, Chandon RC, Shahani KM (1965) A rapid and sensitive assay of muramidase. Proc Soc Exp Biol 119 . $384-386$

Raa J, Roerstad G, Engstad R, Robertsen B (1992) The use of immunostimulants to increase resistance of aquatic organisms to microbial infections. Dis Asian Aquacult 1:39-50

Robertsen B, Rorstad G, Engstad R, Raa J (1990) Enhancement of non-specific disease resistance in Atlantic salmon, Salmo salar L., by a glucan from Saccharomyces cerevisiae cell walls. J Fish Dis 13:391-400

Sakai M (1981) Spontaneous and antibody-dependent haemolysis activities of fish sera and inapplicability of mammalian complements to the immune haemolysis reaction of fishes. Bull Jap Soc Scient Fish 47(8):979-991

Scott AL, Klesius PH (1981) Chemiluminescence: a novel analysis of phagocytosis in fish. In: International Symposium on Fish Biologics: Serodiagnostics and Vaccines, Leetown, W. Va., USA, 1981. Dev Biol Stand 49:243-254

Siwicki AK, Anderson DP, Dixon OW (1989) Comparisons of nonspecific and specific immunomodulation by oxolinic acid, oxytetracycline and levamisole in salmonids. Vet Immunol Immunopathol 23:195-200

Siwicki AK, Anderson DP, Rumsey GL (1994) Dietary intake of immunostimulants by rainbow trout affects non-specific immunity and protection against furunculosis. Vet Immunol Immunopathol 41:125-139

Vigneulle M (1991) Vaccination par voie orale de la truite arcen-ciel, Oncorhynchus mykiss Waibaum, contre la yersiniose à Yersinia ruckeri. Thèse de Doctorat, Universite de Bretagne Occidentale, Brest

Yano $\mathrm{T}$ (1992) Assays of hemolytic complement activity. In: Stolen JS, Fletcher TC, Anderson DP, Kaattari SL, Rowley AF (eds) Techniques in fish immunology. SOS Publications, Fair Haven, NJ, p 131-142

Yano T, Matsuyama H, Mangindaan REP (1991) Polysaccharide-induced protection of carp, Cyprinus carpio L., against bacterial infection. J Fish Dis 14:577-582

Yoshida T, Kruger R, Inglis V (1995) Augmentation of nonspecific protection in African catfish, Clarias gariepinus (Burchell), by the long-term oral administration of immunostimulants. J Fish Dis 18:195-198

Manuscript first received: December 14, 1995

Revised version accepted: February 20, 1996 